\title{
Vascular complications of black patients with type 2 diabetes mellitus in Southern Brazil
}

\author{
F. Gerchman 1,2 , C.M. Zanatta ${ }^{1,2}$, L.M. Burttet ${ }^{1,2}$, P.X. Picon ${ }^{1,2}$, H.R.K. Lisboa ${ }^{3}$, \\ S.P. Silveiro, ${ }^{1,2}$, J.L. Gross ${ }^{1,2}$ and L.H. Canani ${ }^{1,2}$ \\ ${ }^{1}$ Serviço de Endocrinologia, Hospital de Clínicas de Porto Alegre, Porto Alegre, RS, Brasil \\ 2Universidade Federal do Rio Grande do Sul, Porto Alegre, RS, Brasil \\ ${ }^{3}$ Faculdade de Medicina, Universidade de Passo Fundo, Passo Fundo, RS, Brasil
}

Correspondence to: F. Gerchman, Serviço de Endocrinologia, Hospital de Clínicas de Porto Alegre, Rua Ramiro Barcelos, 2350, Prédio 12, 4 andar, 90035-003 Porto Alegre, RS, Brasil

Fax: +55-51-2101-8177. E-mail: fgerchman@terra.com.br

\begin{abstract}
Ethnicity has been shown to be associated with micro- and macrovascular complications of diabetes in European and North American populations. We analyzed the contribution of ethnicity to the prevalence of micro- and macrovascular complications in Brazilian subjects with type 2 diabetes attending the national public health system. Data from 1810 subjects with type 2 diabetes (1512 whites and 298 blacks) were analyzed cross-sectionally. The rates of ischemic heart disease, peripheral vascular disease, stroke, distal sensory neuropathy, and diabetic retinopathy were assessed according to self-reported ethnicity using multiple logistic regression models. Compared to whites, black subjects [odds ratio $=1.72(95 \% \mathrm{Cl}=1.14-2.6)$ ] were more likely to have ischemic heart disease when data were adjusted for age, sex, fasting plasma glucose, HDL cholesterol, hypertension, smoking habit, and serum creatinine. Blacks were also more likely to have end-stage renal disease [3.2 (1.7-6.0)] and proliferative diabetic retinopathy [1.9 (1.1-3.2)] compared to whites when data were adjusted for age, sex, fasting plasma glucose, HDL cholesterol, hypertension, and smoking habit. The rates of peripheral vascular disease, stroke and distal sensory neuropathy did not differ between groups. The higher rates of ischemic heart disease, end-stage renal disease and proliferative diabetic retinopathy in black rather than in white Brazilians were not explained by differences in conventional risk factors. Identifying which aspects of ethnicity confer a higher risk for these complications in black patients is crucial in order to understand why such differences exist and to develop more effective strategies to reduce the onset and progression of these complications.
\end{abstract}

Key words: Ethnicity; Diabetes mellitus; Chronic complications

Research partially supported by CNPq (\#409721/2006-9) and Fundo de Incentivo à Pesquisa e Eventos do Hospital de Clínicas de Porto Alegre (FIPE-HCPA). L.H. Canani was the recipient of a post-doctoral grant (\#127/03-5), and F. Gerchman was the recipient of a fellowship from CAPES (\#0093/05-0).

Received January 11, 2008. Accepted July 4, 2008

\section{Introduction}

Type 2 diabetes mellitus (DM2) is the main cause of end-stage renal disease (ESRD), blindness and non-traumatic amputations (1). Additionally, DM2 is considered to be an important cause of ischemic heart disease (IHD) and stroke (1). The main risk factors involved in the development of these micro- and macrovascular complications are the duration of diabetes, hyperglycemia, hypertension, dyslipidemia, and smoking (2). Genetic factors also seem to play a role in the predisposition to micro- and macrovascular disease $(3,4)$. We have demonstrated that diabetic nephropathy (DN) clusters in some families with DM2 and that relatives of subjects with $\mathrm{DN}$ also have a higher prevalence of cardiovascular risk factors $(5,6)$. In addition, ethnicity may contribute to the development of these complications (7).

Although a higher IHD rate has been reported in black patients with DM compared to white patients in some studies $(8,9)$, other investigators did not confirm this obser- 
vation (10-12). There are also conflicting data about peripheral vascular disease (PVD) (13-15), and most of the data regarding the ethnic distribution of this complication are based on amputation endpoint studies $(10,12,16)$.

Regarding diabetic microangiopathic complications, the incidence of ESRD $(10,12,17-19)$ and the frequency of severe diabetic retinopathy (DR) (20) are higher among black patients with DM2 compared to whites. Two epidemiological studies that investigated which factors are related to distal sensory neuropathy in addition to hyperglycemia did not demonstrate an association between ethnicity and this complication $(21,22)$.

Based on the fact that the combination of interventions to control hyperglycemia, dyslipidemia, high blood pressure and smoking cessation significantly reduces the incidence of these complications but does not prevent their development in all subjects (23), the definition of new risk factors that could potentially be involved in their development is crucial in identifying subjects at risk $(1,2)$. In addition, the establishment of an association between ethnicity and diabetic complications in a population other than that of American and European background would be beneficial to our understanding of the contribution of ethnicity as a determinant of diabetic vasculopathy. Thus, the aim of the present study was to compare the prevalence of diabetic micro- and macrovascular complications in Brazilian subjects receiving assistance from the national public health system according to their ethnicity.

\section{Material and Methods}

\section{Patients}

A total of 1810 patients with DM2 were analyzed from a multicenter study that began recruiting patients in Brazil in 2002. The study was designed to identify factors involved in the development of chronic micro- and macrovascular complications of DM, and included 4 centers at general hospitals in the State of Rio Grande do Sul, Brazil. All patients with DM2 attending the Endocrine Clinics and dialysis units of these hospitals were invited to participate. Inclusion criteria were: DM2 according to World Health Organization $(\mathrm{WHO}$ ) criteria (age $\geq 35$ years and absence of insulin requirement in the first 5 years after diagnosis). Chronic diabetic complications (DR, DN, and distal sensory neuropathy, DSN) were assessed in the entire sample. Information about macrovascular disease was available for 1177 patients. Ethnicity was classified based on self-reported skin color and recorded as white, black, white-black admixture (mixed) and "other". Mixed subjects $(N=181)$ were excluded from this analysis because of the limitation of this definition (24). Subjects with "other" ethnic origins $(\mathrm{N}=77)$ were also excluded because of their small sample size.

Patients underwent a standard clinical and laboratory evaluation as previously described (5). Briefly, information about age, known DM duration, smoking habits, arterial blood pressure, and anthropometric measurements was collected. Metabolic syndrome was diagnosed according to WHO guidelines, by the presence of DM together with two or more of the following (25): obesity (body mass index $>30 \mathrm{~kg} / \mathrm{m}^{2}$ and/or waist-hip ratio $>0.90$ for men and $>0.85$ for women), hypertension (blood pressure $\geq 140 / 90 \mathrm{mmHg}$ or use of antihypertensive drugs), dyslipidemia (triglycerides $\geq 150 \mathrm{mg} / \mathrm{dL}$ and/or HDL cholesterol $<40 \mathrm{mg} / \mathrm{dL}$ for men and $<45 \mathrm{mg} / \mathrm{dL}$ for women) or increased urinary albumin excretion (UAE; $>20 \mu \mathrm{g} / \mathrm{min}$ or $>17 \mathrm{mg} / \mathrm{L}$ ) (26).

\section{Assessment of diabetic complications}

DR was assessed by ophthalmoscopic examination through dilated pupils performed by an ophthalmologist and classified as absent, non-proliferative DR, or proliferative DR. DN was evaluated by UAE measurements. Patients were classified as normo- (UAE $<20 \mu \mathrm{g} / \mathrm{min}$ or $<17$ $\mathrm{mg} / \mathrm{L}$ ), micro- (UAE $20-200 \mu \mathrm{g} / \mathrm{min}$ or $17-174 \mathrm{mg} / \mathrm{L}$ ), or macroalbuminuric (UAE $\geq 200 \mu \mathrm{g} / \mathrm{min}$ or $>174 \mathrm{mg} / \mathrm{L}$ ) (26). UAE values were confirmed by at least two of three measurements made 3 to 6 months apart. Patients with ESRD being treated at dialysis units were also included. DSN was diagnosed by typical symptoms, abnormal Achilles tendon reflexes, vibration test or sensory perception determined with a 10-g Semmes-Weinstein monofilament applied to the hallux of each foot. PVD was diagnosed in the presence of intermittent claudication (WHO Cardiovascular Questionnaire) (6) and/or the absence of posterior tibial pulse and pedial pulse upon clinical examination. Cerebrovascular disease (stroke) was established by a history and/or the presence of compatible findings. IHD was diagnosed by the presence of angina or possible infarct according to the WHO Cardiovascular Questionnaire, and/or in the presence of resting (Minnesota code)/stress ECG test abnormalities, and/or in the presence of perfusion abnormalities (fixed or variable) upon myocardial scintigraphy at rest and after dipyridamole administration (6). The Ethics Committees of the institutions participating in the study approved the protocol and written informed consent was obtained from all participants.

\section{Laboratory measurements}

UAE was measured in a 24 -h timed or in a random sterile urine sample by immunoturbidimetry (Microalb, Ames-Bayer, USA; intra- and interassay coefficients of variation: 4.5 and $11.0 \%$, respectively). 
Glucose levels were determined by the glucose oxidase method, creatinine by the Jaffé reaction, hemoglobin A1c (HbA1c) by ion-exchange HPLC (Merck-Hitachi L9100 Glycated Hemoglobin Analyzer, Germany; reference range: 4.7-6.0\%; certified by the American National Glycohemoglobin Standardization Program, NGSP), and triglycerides and cholesterol levels by enzymatic methods. LDL cholesterol was calculated using the Friedewald equation.

\section{Statistical analysis}

Data are reported as mean $\pm \mathrm{SD}$, median (range) or absolute numbers and percentages. Continuous data were analyzed by ANOVA and variables with non-normal distribution were log-transformed for analysis. The chi-square test was used for categorical data. Multiple logistic regression analysis was used to assess the effect of ethnicity controlled for possible confounding factors. The inclusion of independent variables was based on clinical relevance and/or statistical association with ethnicity in univariate analyses. A P value (two-sided) $<0.05$ was considered to be significant.

\section{Results}

\section{Patient description}

A total of 1810 patients with DM2 were identified (1512 white, 298 black). Complete information about diabetic microvascular complications was available for all patients. Information regarding macrovascular complications was completed for 1177 patients. The main clinical and laboratory characteristics are shown in Table 1. White patients were older and had a longer known DM duration than black patients. The prevalence of current smokers and hypertension as well as systolic and diastolic blood pressure levels, body mass index, fasting plasma glucose, $\mathrm{HbA1c}$, total and LDL cholesterol levels did not differ between groups. The proportion of subjects on therapy with statins, acetylsalicylic acid and angiotensin-converting enzyme inhibitors did not differ between groups.

Black patients had higher creatinine and HDL cholesterol levels, but a lower waist-hip ratio and lower triglyceride levels than white patients. The prevalence of metabolic syndrome was lower among black patients than among white patients.

\section{Macrovascular disease}

A total of 1177 patients were evaluated for macrovascular disease (1037 white, 140 black). Black patients had a higher prevalence of IHD than white patients (44.3 vs $34.8 \%, P=0.006$; Table 2). The prevalence of PVD and stroke did not differ between groups $(P>0.05)$.

\section{Microvascular disease}

ESRD was more frequent among black than white patients (22.9 vs $12.8 \%, \mathrm{P}<0.001$; Table 2$)$. The prevalence of less severe forms of DN (micro- and macroalbuminuria) did not differ between whites and blacks $(P>0.05)$. Proliferative DR was more frequent among blacks than whites (28.4 vs $20.2 \%, P=0.004)$ while the prevalence of non-proliferative $D R$ did not differ between groups $(P>$ 0.05). The prevalence of DSN also did not differ between blacks and whites (34.8 vs $31.7 \%, \mathrm{P}=0.542)$.

Table 1. Clinical and laboratory characteristics of the diabetic patients classified on the basis of ethnicity.

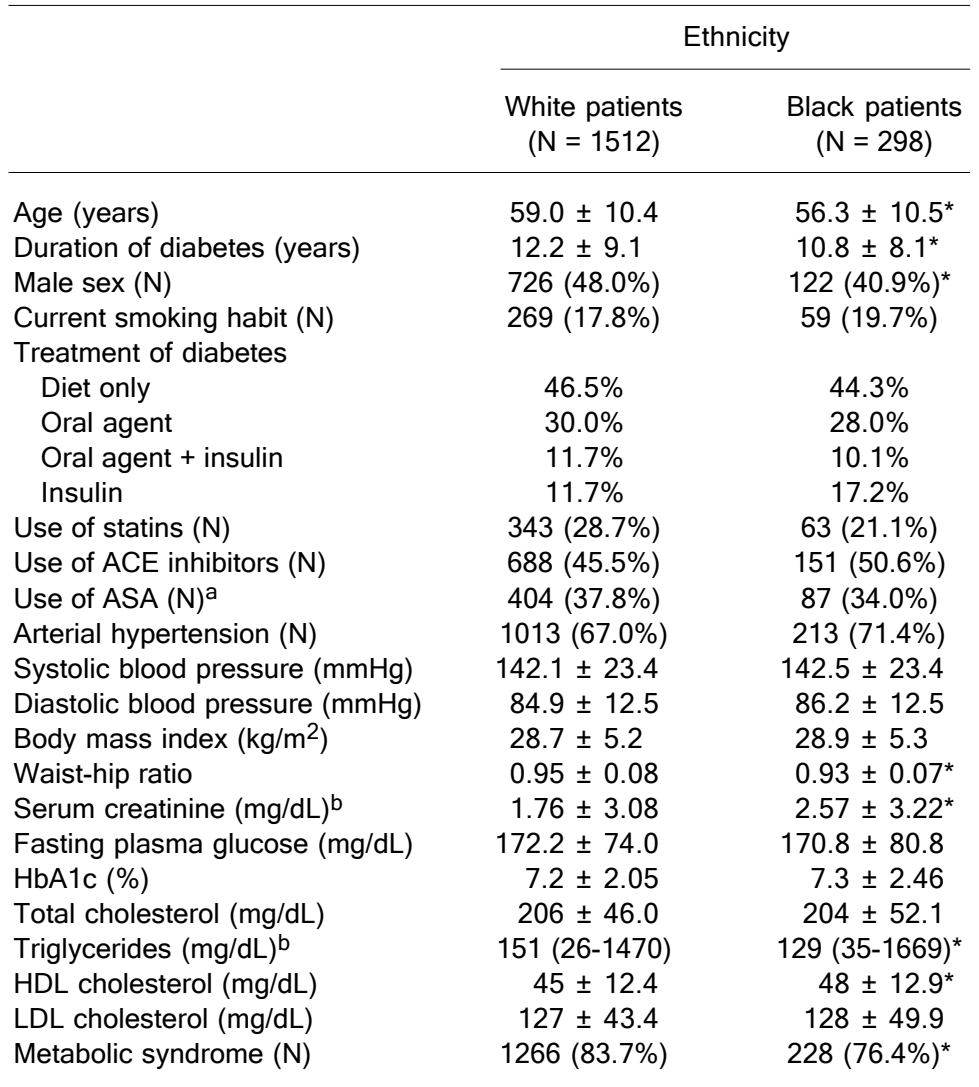

Data are reported as mean $\pm \mathrm{SD}$, median (range), or number of patients with percent in parentheses. aData available for 1324 subjects. bStatistical analysis performed on log-transformed data. $\mathrm{ACE}=$ angiotensin-converting enzyme; $\mathrm{ASA}=$ acetylsalicylic acid; $\mathrm{HbA} 1 \mathrm{c}=$ hemoglobin $\mathrm{A} 1 \mathrm{c}$.

${ }^{*} \mathrm{P}<0.05$ compared to white patients (ANOVA or chi-square test). 
Multivariate analysis: adjustments for factors possibly related to micro- and macrovascular complications

The association of IHD, ESRD, and proliferative DR according to ethnicity controlled for sex, age, smoking habits, fasting plasma glucose, HDL cholesterol, and the presence of hypertension in multivariate analysis is shown in Table 3. Three independent logistic regression models were constructed with IHD, ESRD, and proliferative DR as dependent variables. For IHD, serum creatinine levels were also included in the model. Black patients had a $59 \%$ higher prevalence of IHD compared to white patients. Black patients also had a higher frequency of ESRD and proliferative DR. Replacing age with diabetes duration did not affect the results in any of these models (IHD: OR = $1.46,95 \% \mathrm{Cl}=1.01-2.39$; $\mathrm{ESRD}: \mathrm{OR}=2.13,95 \% \mathrm{Cl}=1.20$ 3.77; proliferative $\mathrm{DR}$ : $\mathrm{OR}=2.00,95 \% \mathrm{Cl}=1.19-3.36$ ). When glucose was replaced with $\mathrm{HbA} 1 \mathrm{c}$ the results did not change (IHD: OR = 1.60, 95\%Cl = 1.11-2.30; ESRD: OR = 2.47, $95 \% \mathrm{Cl}=1.70-3.60$; proliferative $\mathrm{DR}$ : $\mathrm{OR}=1.84$, $95 \% \mathrm{Cl}=1.26-2.69)$.

\section{Discussion}

The results of this cross-sectional study indicate that the prevalence of IHD, ESRD and proliferative DR is higher in Brazilian black patients with DM2 compared to white patients assisted by the national health system. These findings were still present even after controlling for potential confounders. On the other hand, the prevalence of micro- and macroalbuminuria, as well as non-proliferative DR, PVD, DSN and stroke did not differ between black and white Brazilian diabetic subjects.

Black-white differences in the rate of micro- and macro-

Table 2. Prevalence of macro- and microvascular complications in patients classified according to ethnicity.

\begin{tabular}{|c|c|c|}
\hline & $\begin{array}{l}\text { White patients } \\
\qquad(\mathrm{N}=1037)\end{array}$ & $\begin{array}{l}\text { Black patients } \\
\qquad(\mathrm{N}=140)\end{array}$ \\
\hline \multirow{4}{*}{$\begin{array}{l}\text { Macrovascular complications } \\
\text { Ischemic heart disease } \\
\text { Peripheral vascular disease } \\
\text { Stroke }\end{array}$} & 361 (34.8\%) & $62(44.3 \%)^{*}$ \\
\hline & $336(32.4 \%)$ & $38(26.8 \%)$ \\
\hline & $69(6.3 \%)$ & $8(5.8 \%)$ \\
\hline & $\begin{array}{l}\text { White patients } \\
\qquad(\mathrm{N}=1512)\end{array}$ & $\begin{array}{l}\text { Black patients } \\
\quad(\mathrm{N}=298)\end{array}$ \\
\hline \multicolumn{3}{|l|}{ Microvascular complications } \\
\hline End-stage renal disease & $194(12.8 \%)$ & $64(22.9 \%)^{*}$ \\
\hline Proliferative diabetic retinopathy & $305(20.2 \%)$ & $85(28.4 \%)^{*}$ \\
\hline Distal sensory neuropathy & $479(31.7 \%)$ & $104(34.8 \%)$ \\
\hline
\end{tabular}

Data are reported as number of patients with percent in parentheses. ${ }^{*} \mathrm{P}<0.05$ compared to white patients (chi-square test). vascular complications have been observed in some studies (reviewed in Ref. 7). It has been suggested that part of these black-white differences may be related to a higher prevalence of hypertension among blacks compared to whites $(11,19)$. However, in our study, blood pressure levels and the prevalence of hypertension were not different between groups. Furthermore, while adjusting for multiple confounders in multivariate models, the association still held true even after the inclusion of hypertension in the model. Therefore, hypertension could not account for our findings. Age was lower and diabetes duration was shorter in blacks. In fact, we would expect even a greater blackwhite difference in the prevalence of these complications if whites and blacks were of similar age and had a similar duration of diabetes. Other possible factors related to micro- and macrovascular complications of diabetes, such as differences in the levels of $\mathrm{HbA} 1 \mathrm{c}$ or the prevalence of obesity, were not different between blacks and whites in the present study.

Some studies have shown a lower rate of IHD among blacks with DM2 (10-12). In the Multiple Risk Factor Intervention Trial (MRFIT) (11), the assessment of vascular complications was based on death certificates and these results could be explained in part by differences in death certificate registration between racial/ethnic groups. In two other studies exploring data sets of the Kaiser Permanente Medical Care Program (10) and of the Veterans Affairs Health System (12), differences in the rates of diabetic complications were also found between blacks and whites.

Table 3. Multivariate analysis models for the relationship between ethnicity and ischemic heart disease, end-stage renal disease and proliferative diabetic retinopathy in patients with type 2 diabetes mellitus.

\begin{tabular}{lc}
\hline & Odds ratio $(95 \% \mathrm{Cl})$ \\
\hline $\begin{array}{l}\text { Ischemic heart disease } \\
\text { White }\end{array}$ & - \\
$\quad$ Black & $1.72(1.14-2.60)^{*}$ \\
End-stage renal disease & b \\
$\quad$ White & - \\
Black & $3.22(1.72-6.00)^{*}$ \\
Proliferative retinopathy & \\
$\quad$ White & - \\
Black & $1.87(1.08-3.22)^{*}$ \\
\hline
\end{tabular}

aAdjusted for age, sex, fasting plasma glucose, HDL cholesterol, hypertension, smoking habits, and serum creatinine. ${ }^{b}$ Adjusted for age, sex, fasting plasma glucose, HDL cholesterol, smoking habits, and hypertension.

${ }^{*} \mathrm{P}<0.05$ compared to white patients (multiple logistic regression analysis). 
In both studies, a higher prevalence of microvascular complications and a lower prevalence of IHD were found in blacks than in whites. In contrast to these epidemiological studies, we conducted a cross-sectional study specifically designed to investigate the mechanisms involved in the etiology of diabetic complications. This would decrease the chances of potential errors related to misclassification of complications associated with DM.

The prevalence of micro- and macroalbuminuria, elevated serum creatinine levels and ESRD has been reported to be increased in black patients compared to whites $(10,12,17-19,27-30)$. In the present study, the rate of ESRD was significantly higher in black patients, even after controlling for other possible risk factors, confirming previously reported data. However, there was no difference in the prevalence of micro- or macroalbuminuria. A similar pattern was observed for DR, with only the prevalence of proliferative DR being increased among blacks. Moreover, similar findings were obtained in the Veterans Affairs Diabetes Trial (VADT), in which a higher prevalence of the severe forms of DR was detected in a predominantly male population (20). This suggests that subjects of African ancestry are at higher risk of progression to severe forms of DN and DR, but are not at a higher risk of developing mild forms of these complications. Overestimation of black individuals on dialysis could be a potential confounder. However, about $80 \%$ of the ESRD patients had started dialysis only recently, a fact that would decrease the chance of survival bias. An alternative explanation could be that ethnicity does not lead to the development of incipient DN (microalbuminuria) or mild forms of $\mathrm{DR}$, but once these conditions are installed, subjects of African descent would be more susceptible to the progression of these complications to advanced stages, independently of factors such as blood pressure, hyperglycemia or dyslipidemia.

A major concern to be addressed is the definition of ethnicity. In the present study, self-reported skin color was used as a surrogate of the racial/ethnic group definition. In a study conducted at our institution, there was an excellent rate of agreement between self-reported ethnicity and that determined by a trained observer, differentiating black and white subjects (24). The use of genetic markers to identify ethnic groups might improve this distinction. Nevertheless, using an ancestrality index based on these genetic markers, one study showed that subjects from southern Brazil classified as white based on skin color had an index similar to that of white subjects from Portugal (31). There was no significant overlap of the ancestrality index of white Brazilians and of individuals from São Tomé Island, that represents the African origin of the Brazilian population (31). On the other hand, another study of the same group, where molecular tools of $\mathrm{Y}$-chromosome and mitochondrial DNA analysis were used, has suggested a much higher level of genetic admixture than had previously been thought to exist between whites and blacks in Brazil (Pena SD, personal communication, http://sbbq.iq.usp.br/arquivos/2008/ cdlivro/palestras/CF01_PenaSDJ.pdf).

There are potential limitations to our study that should be noted. First, we were not able to assess whether differences in diet, social background or education between whites and blacks are responsible for our findings. Additionally, differences in health care access provided to black subjects in Europe and the United States have been proposed as important determinants of the differences in the rates of PVD found between white and black subjects (13). However, we would not expect major socioeconomic or differences in assistance provided to white and black patients since all subjects were attending the same health system. In fact, we have shown that there is no difference in the proportion of white and black subjects on treatment with antidiabetic medications, statins, acetylsalicylic acid and angiotensin-converting enzyme inhibitors. Even if these factors were involved in the disparities found in the rates of micro- and macrovascular complications between whites and blacks, this information would help clinicians in deciding to decrease or increase their surveillance of these complications while assisting their patients. Second, the cross-sectional study design makes it difficult to infer causality between ethnicity and diabetic complications. Thus, while showing disparities in the rates of macro- and microvascular complications according to ethnicity, our results do not address which elements of ethnicity confer a greater risk of these complications to black patients.

\section{References}

1. Harris MI. Summary. In: Harris MI, Cowie CC, Stern MP, Boyko EJ, Reiber GE, Bennett PH (Editors), Diabetes in America. 2nd edn. Bethesda: National Diabetes Data Group, National Institutes of Health, National Institute of Diabetes and Digestive and Kidney Diseases. NIH publication No. 95-
1468; 1995. p 1-13.

2. Clark CM Jr, Lee DA. Prevention and treatment of the complications of diabetes mellitus. N Engl J Med 1995; 332: 1210-1217.

3. Placha G, Canani LH, Warram JH, Krolewski AS. Evidence 
for different susceptibility genes for proteinuria and ESRD in type 2 diabetes. Adv Chronic Kidney Dis 2005; 12: 155-169.

4. Casas JP, Cooper J, Miller GJ, Hingorani AD, Humphries $\mathrm{SE}$. Investigating the genetic determinants of cardiovascular disease using candidate genes and meta-analysis of association studies. Ann Hum Genet 2006; 70: 145-169.

5. Canani LH, Gerchman F, Gross JL. Familial clustering of diabetic nephropathy in Brazilian type 2 diabetic patients. Diabetes 1999; 48: 909-913.

6. Canani LH, Gerchman F, Gross JL. Increased familial history of arterial hypertension, coronary heart disease, and renal disease in Brazilian type 2 diabetic patients with diabetic nephropathy. Diabetes Care 1998; 21: 1545-1550.

7. Carter JS, Pugh JA, Monterrosa A. Non-insulin-dependent diabetes mellitus in minorities in the United States. Ann Intern Med 1996; 125: 221-232.

8. Jha AK, Varosy PD, Kanaya AM, Hunninghake DB, Hlatky MA, Waters DD, et al. Differences in medical care and disease outcomes among black and white women with heart disease. Circulation 2003; 108: 1089-1094.

9. Keil JE, Sutherland SE, Knapp RG, Lackland DT, Gazes $\mathrm{PC}$, Tyroler HA. Mortality rates and risk factors for coronary disease in black as compared with white men and women. $N$ Engl J Med 1993; 329: 73-78.

10. Karter AJ, Ferrara A, Liu JY, Moffet HH, Ackerson LM, Selby JV. Ethnic disparities in diabetic complications in an insured population. JAMA 2002; 287: 2519-2527.

11. Vaccaro O, Stamler J, Neaton JD. Sixteen-year coronary mortality in black and white men with diabetes screened for the Multiple Risk Factor Intervention Trial (MRFIT). Int $J$ Epidemiol 1998; 27: 636-641.

12. Young BA, Maynard C, Boyko EJ. Racial differences in diabetic nephropathy, cardiovascular disease, and mortality in a national population of veterans. Diabetes Care 2003; 26: 2392-2399.

13. Leggetter $\mathrm{S}$, Chaturvedi N, Fuller JH, Edmonds ME. Ethnicity and risk of diabetes-related lower extremity amputation: a population-based, case-control study of African Caribbeans and Europeans in the United Kingdom. Arch Intern Med 2002; 162: 73-78.

14. Adler AI, Stevens RJ, Neil A, Stratton IM, Boulton AJ, Holman RR. UKPDS 59: hyperglycemia and other potentially modifiable risk factors for peripheral vascular disease in type 2 diabetes. Diabetes Care 2002; 25: 894-899.

15. Newman AB, Siscovick DS, Manolio TA, Polak J, Fried LP, Borhani NO, et al. Ankle-arm index as a marker of atherosclerosis in the Cardiovascular Health Study. Cardiovascular Heart Study (CHS) Collaborative Research Group. Circulation 1993; 88: 837-845.

16. Lavery LA, Ashry HR, van Houtum W, Pugh JA, Harkless LB, Basu S. Variation in the incidence and proportion of diabetes-related amputations in minorities. Diabetes Care 1996; 19: 48-52.
17. US Renal Data System. USRDS Annual Report. Bethesda: National Institutes of Health, National Institute of Diabetes and Digestive and Kidney Diseases; 2003.

18. Brancati FL, Whittle JC, Whelton PK, Seidler AJ, Klag MJ. The excess incidence of diabetic end-stage renal disease among blacks. A population-based study of potential explanatory factors. JAMA 1992; 268: 3079-3084.

19. Cowie CC, Port FK, Wolfe RA, Savage PJ, Moll PP, Hawthorne VM. Disparities in incidence of diabetic end-stage renal disease according to race and type of diabetes. N Engl J Med 1989; 321: 1074-1079.

20. Emanuele N, Sacks J, Klein R, Reda D, Anderson R, Duckworth $\mathrm{W}$, et al. Ethnicity, race, and baseline retinopathy correlates in the Veterans Affairs Diabetes Trial. Diabetes Care 2005; 28: 1954-1958.

21. Harris M, Eastman R, Cowie C. Symptoms of sensory neuropathy in adults with NIDDM in the U.S. population. Diabetes Care 1993; 16: 1446-1452.

22. Tesfaye S, Chaturvedi N, Eaton SE, Ward JD, Manes C, lonescu-Tirgoviste $\mathrm{C}$, et al. Vascular risk factors and diabetic neuropathy. N Engl J Med 2005; 352: 341-350.

23. Gaede $P$, Vedel $P$, Larsen $N$, Jensen GV, Parving $H H$, Pedersen $O$. Multifactorial intervention and cardiovascular disease in patients with type 2 diabetes. N Engl J Med 2003; 348: 383-393.

24. Fuchs SC, Guimaraes SM, Sortica C, Wainberg F, Dias KO, Ughini $\mathrm{M}$, et al. Reliability of race assessment based on the race of the ascendants: a cross-sectional study. BMC Public Health 2002; 2: 1.

25. World Health Organization. Definition, diagnosis and classification of diabetes mellitus and its complications, Part 1, diagnosis and classification of diabetes mellitus. Geneva: WHO; 1999.

26. Zelmanovitz T, Gross JL, Oliveira JR, Paggi A, Tatsch M, Azevedo MJ. The receiver operating characteristics curve in the evaluation of a random urine specimen as a screening test for diabetic nephropathy. Diabetes Care 1997; 20: 516519.

27. Young BA, Katon WJ, Von Korff M, Simon GE, Lin EH, Ciechanowski PS, et al. Racial and ethnic differences in microalbuminuria prevalence in a diabetes population: the pathways study. J Am Soc Nephrol 2005; 16: 219-228.

28. Savage S, Nagel NJ, Estacio RO, Lukken N, Schrier RW. Clinical factors associated with urinary albumin excretion in type II diabetes. Am J Kidney Dis 1995; 25: 836-844.

29. Cowie CC. Diabetic renal disease: racial and ethnic differences from an epidemiologic perspective. Transplant Proc 1993; 25: 2426-2430.

30. Crook ED. Diabetic renal disease in African Americans. Am J Med Sci 2002; 323: 78-84.

31. Parra FC, Amado RC, Lambertucci JR, Rocha J, Antunes $\mathrm{CM}$, Pena SD. Color and genomic ancestry in Brazilians. Proc Natl Acad Sci U S A 2003; 100: 177-182. 